\title{
Risk assessment for international construction joint ventures in Vietnam
}

\author{
Sy Tien Do ${ }^{1,2}$, , Veerasak Likhitruangsilp ${ }^{2}$, Tran Tuan Kiet ${ }^{2}$, Phong Thanh Nguyen ${ }^{2,3}$ \\ ${ }^{1}$ Faculty of Civil Engineering, Bach Khoa University (BKU), Ho Chi Minh, Vietnam \\ ${ }^{2}$ Construction Engineering and Management Division, Chulalongkorn University (CU), Bangkok, Thailand \\ ${ }^{3}$ Department of Project Management, Ho Chi Minh City Open University (HCMCOU), Ho Chi Minh, Vietnam
}

\section{A RT I C LE IN F O}

Article history:

Received 13 March 2017

Received in revised form

21 April 2017

Accepted 18 May 2017

Keywords:

Risk assessment

International construction joint

venture

Vietnam

\begin{abstract}
A B S T R A C T
Joint venture (JV) form has been adopted in construction industries worldwide because of the huge benefits, one of which is that foreign companies can share their work experiences and resources with local companies that understand cultural, political, and legal factors in their countries well. Even though JV is an attractive option for international construction business management, it is also extremely risky due to size, complexity, and multifaceted operations of JV projects. The objective of this study is to assess risk factors affecting three performance stages of international construction joint venture (ICJV) projects in Vietnam namely Startup, Operation, and Dismantle. Based on the findings through questionnaire surveys and in-depth interviews, critical risk factors were first identified and compared among three stages to appreciate their differences and similarities. Finally, the results of this paper were (a) the characteristics of risk factors in each stage, (b) startup stage of ICJV contained many potential risk factors should be most concerned, and (c) trend analysis in different stages of ICJV projects.
\end{abstract}

(C) 2017 The Authors. Published by IASE. This is an open access article under the CC BY-NC-ND license (http://creativecommons.org/licenses/by-nc-nd/4.0/).

\section{Introduction}

After Vietnam joined the World Trade Organization (WTO) on November 7, 2006, foreign investment capital in Vietnam has increased continuously within construction industry that became an important section in national development. However, most of local companies are inexperienced, have weak managerial skill, and lack funds. Therefore, most large projects, including foreign direct investment projects and official development assistance (ODA) projects, were the market for foreign companies or international joint venture companies.

The form of joint venture cooperation is very popular in Vietnam nowadays because foreign contractors are more experienced and possess more resources, whereas local contractors understand cultural, political, and legal factors in their countries better. In spite of its numerous merits, it is highly risky for all contractors to implement this business scheme successfully due to size, complexity, and multifaceted operations of JV projects (Bing et al.,

\footnotetext{
* Corresponding Author.

Email Address: Sy.dotien@yahoo.com (S. T. Do)

https://doi.org/10.21833/ijaas.2017.06.015

2313-626X/C 2017 The Authors. Published by IASE.

This is an open access article under the CC BY-NC-ND license

(http://creativecommons.org/licenses/by-nc-nd/4.0/)
}

1999; Andrew et al., 2000; Shen et al., 2001). In developing countries, the number of failure JVs is quite high, more than $50 \%$ of JV companies in developing countries, as Bing et al. (1999) mentioned in their studies. Since a limited number of research works investigated the risks related to the ICJVs in Vietnam, the objectives of this paper are to assess critical risk factors and to understand the tendency of risk factors groups in three implementation stages of ICJV projects in Vietnam.

\section{Literature review}

Comparing with other industries, construction often encounters with more risks. Construction projects always play against abundant challenges and critical risks that affect project objectives at different levels such as project performance, organization, and environment. Several previous research works investigated risk factors affecting the performance of construction projects. Risk management is a formal and orderly process for systematically identifying, analyzing, and responding to risks throughout the life cycle of a project to yield the optimum degree of risk elimination, mitigation, and control (Wang et al., 2004; Soghe and Balasbaneh, 2015). Risk identification is an important step to set up the risk framework for controlling project risks. Various techniques can be 
used to identify construction risks, including checklists, brainstorming, sources of risk (Shen et al., 2001; Han et al., 2008), risk breakdown structure (Zhi, 1995; Ezeldin and Orabi, 2006; Sameh, 2008) and so on. Risk assessment is also a significant step to analysis the important level of risk factors to project objectives. There are two methods to assess risks in construction projects, such as qualitative and quantitative methods (Smith et al., 1999). Besides, risk response is an important step for mitigating project risks. The risk response strategies entail risk mitigation, risk transfer, risk acceptance, and risk avoidance (Smith et al., 1999; Flanagan and Norman, 1993); and risk response strategies adopted by contract, insurance, and retention management (Zhi, 1995).

A large number of constructions JV projects, more than $50 \%$ of JV projects in developing countries, (Beamish, 1993) have failed to achieve their goal and objectives (Geringer and Hebert, 1991). This is because construction JV encompasses many participants leading to complex organization and environment. The ICJV projects are usually very large and complex. A large number of parties, including contractors, subcontractors, and nominated subcontractors/suppliers are associated with the projects. The relationship and information stream among the participants are very complicated.

Construction joint venture risk factors were categorized according to their nature (e.g. management risks, financial risks, market risks) (Shen et al., 2001) or the relationship with organizations (e.g. internal risks, project-specific risks, and external risks) (Bing et al., 1999; Zhang and Zou, 2007). The internal risk group includes risks related to the organization of JV companies. The project-specific risk group entails risks associated with the project performance project. The external risk group involves risks resulting from external environment conditions. Most critical risk factors exist in the JV partners finance, government policies, economic conditions, and project relationship (Bing et al., 1999). In addition, the difference in management systems, technological practice, and cultural background among the partners within joint ventures also contribute to the function of JV (Gale and Luo, 2004). These factors thus need to be addressed throughout the implementation of JV to reduce the likelihood and impact level of the risks. Furthermore, the risk identification can be used to predict the performance, which contributes to the success of ICJVs (Andrew et al., 2000; Ozorhon et al., 2007).

General construction projects and JV projects in particular, often have large size, complex and involve many stages of implementation, such as (1) Startup, (2) Operation, and (3) Dismantle (Bing et al., 1999). Furthermore, based on the research of Andrew et al. (2000), the critical factors that contribute to successful JVs and the risk factors associated with JV operations was considered. Accordingly, twenty-four critical factors for successful operation of JVs are related mainly to areas involving: (1) Pre-Planning (six factors), (2) Partner Selection (seven factors), (3) Negotiation and Policy Agreement (six factors), and (4) Implementation (five factors). Through the respondents' information, the authors concluded the most critical factors in each implementation stages. For instance, in the Initial Set-up Stage, the threat of the JV partner facing financial distress is important to consider. Similarly, in the Operation and Implementation Stage, distrust among employees is perceived to be the most critical risk factor, and in the Dismantling and Defects Liability Period Stage, disagreement in accounting of profit and loss is especially critical.

\section{Research methodology}

In this paper, data were mainly gathered through in-depth interviews and questionnaire surveys. The questionnaire surveys and interviews consisted of three main sections:

(1)Respondent's background information- name, organization, role, position, and experience.

(2)Risk factors affecting ICJV implementation probability and impact of risk factors corresponding to each stage of project, as well as major impacts on project objectives (time, cost, quality, and scope).

(3)Risk response measures - methods adopted by the respondents to eliminate or mitigate risk factors in their ICJV projects.

Fig. 1 illustrates the process of research methodology. The data collection process consisted of two phases: the pilot survey (phase 1) and the large-scale survey (phase 2). In Phase 1, based on the literature review and the pilot interviews, we identified 47 risk factors affecting performance of ICJVs and categorized them into groups (Sy and Likhitruangsilp, 2011). These risk factors were then categorized into three risk groups (Fig. 2), including Internal risks, Project risks, and External risks. A Linker scale was used in this questionnaire survey. The respondents were asked to specify the probability (scale 1 to 5 ) and impact (scale A to E) of risk factors. In Phase 2, we assessed the probability and impact of each risk factor. The Probability and Impact method (Dale, 2005) was applied to assess the level of these risks. The combined risk level (RL) of the certain risk factor can be calculated by using the following formula (Eq. 1):

$R L=P+I-P \times I$

where

$\mathrm{P}=$ risk likelihood (probability) measure, on a scale 0 to 1

I = impact measure, on a scale 0 to 1

All the risks were then classified into three levels, namely, high, medium, and low. In this paper, the cut-off points between the high-risk and the medium-risk levels and between the medium-risk and the low-risk levels lie at $\mathrm{RL}=0.80$ and $\mathrm{RL}=0.45$, respectively. 


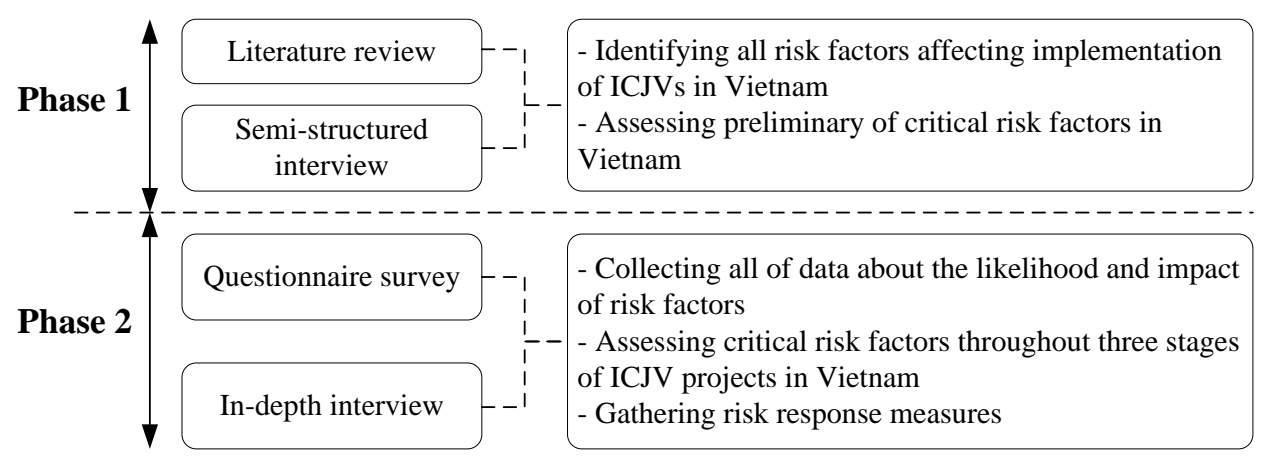

Fig. 1: Research methodology process

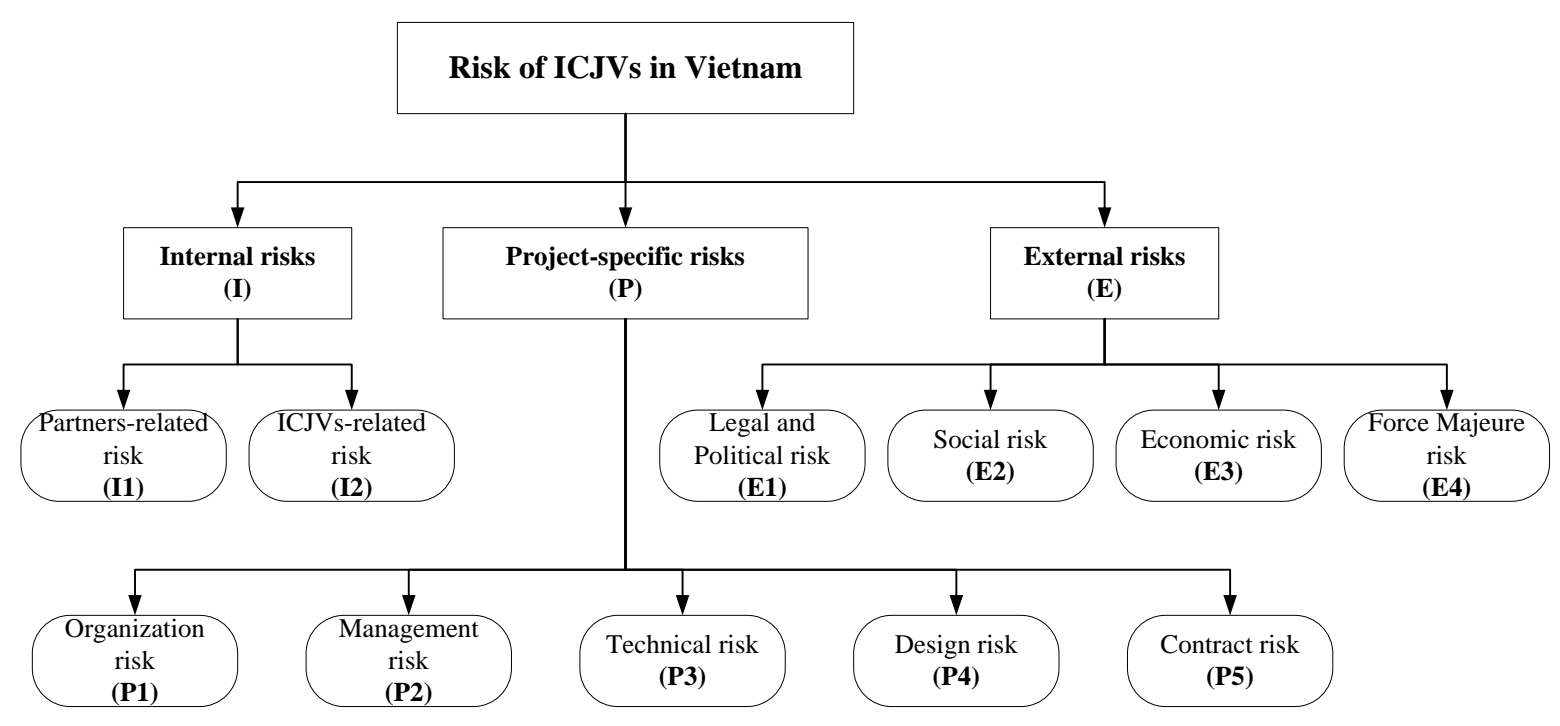

Fig. 2: Risk breakdown structure

Moreover, the tendency of each risk factors group was then analyzed upon the overall average value of probability (P), impact (I), and combined risk level (RL). The overall RL of each group was defined by following formula (Eq. 2):

$R L_{i}=\frac{\sum_{j=1}^{n} R L}{n}$

where

$\mathrm{i}=1-3$ : group of risk factors in ICJV projects

$\mathrm{j}=1-\mathrm{n}$ : risk factor of each risk group

$\mathrm{n}$ : the number of risk factors in each group

\section{Data collection}

In this paper, the participants in the survey were Vietnamese construction contractors, consultants, and project managers that were or are currently JV partners with foreign contractors. They had good experience working on various JVs in major cities in Southern Vietnam. Table 1 illustrates the profile of the participants in the survey, which include 15 respondents from ICJV companies.

According to the respondent's profile, 14 respondents (93.3\%) had experience in construction more than five years. This is consistent with the purpose of this study, which focuses on the project manager and line manager with many years of experience in the construction industry.

Most of the respondents $(66.7 \%)$ worked for main contractors, subcontractors, and consultants and five respondents (33.3\%) worked as consultants for clients. Thus, the large-scale survey covered main stakeholders of the ICJV projects, namely, main contractors, subcontractors, and consultants, all of which directly involved from the initial stage to project completion. Among the projects in this study, $73.3 \%$ were civil projects and $26.7 \%$ were industrial projects.

Risk management is very important for the construction joint venture and the construction industry. As shown in Table 2, all respondents were aware of risk management, 66.7 percentages of the respondents considered that they have good awareness about risk management system. However, they have noted that the Vietnamese companies rarely implemented risk management system. In many cases, the company in Vietnam rarely carried out risk management system.

Therefore, these are the huge matter of Vietnamese construction industry today; practical risk management system has not been widespread and regular used. In Table 2, the proportions of the respondents who considered that risk management be necessary and very necessary are $46.7 \%$ and 
$53.3 \%$, respectively. It also showed that the construction companies in Vietnam merely have a little experience about risk management. Risk management system is primarily based on experience learned from the previous projects, and general management skills.

Table 1: Respondents' profile

\begin{tabular}{lcc}
\hline \multirow{2}{*}{ Category } & \multicolumn{2}{c}{ Respondents } \\
\cline { 2 - 3 } 1. Years of experience & & $\%$ \\
3-5 years & 1 & 6.7 \\
5-10 years & 8 & 53.3 \\
>10 years & 6 & 40 \\
2. Role & & \\
Main contractor & 7 & 46.7 \\
Consultant & 3 & 20 \\
Owner & 5 & 33.3 \\
3. Position & & \\
Directors & 2 & 13.3 \\
Deputy directors & 0 & 0 \\
Project managers & 8 & 53.3 \\
Supervisors & 5 & 33.3 \\
Engineers/Architects & 0 & 0 \\
4. National & & \\
Singapore & 3 & 20 \\
Korea & 1 & 6.7 \\
Japan & 4 & 26.7 \\
China & 3 & 20 \\
Other & 4 & 26.7 \\
\hline
\end{tabular}

Table 2: Perception of risk management

\begin{tabular}{lcc}
\hline \multirow{2}{*}{ Category } & \multicolumn{2}{c}{ Respondents } \\
\cline { 2 - 3 } & Number & $\%$ \\
\hline 1. Perception of risk management & & \\
Unknown & 0 & 0 \\
Heard of it & 5 & 33.3 \\
Known & 9 & 60 \\
Know very well & 1 & 6.7 \\
2. Necessary of risk management & & \\
Unnecessary & 0 & 0 \\
Necessary & 7 & 46.7 \\
Very necessary & 8 & 53.3 \\
\hline
\end{tabular}

\section{Results and discussions}

\subsection{Risk factors affecting ICJV projects in Vietnam}

A risk coding system, as shown in Fig. 3, was developed to help organize all of the risk factors (e.g I1.2 is referred to 'policy changes in your partner's parent company toward ICJV'). Fig. 4 lists 47 risk factors affecting the performance of ICJVs (Sy and Likhitruangsilp, 2011). Through the literature review and the in-depth interviews, these risk factors can be categorized into three main groups:

- Internal risks (I) include the risk factors in ICJV itself, subdivided into two subcategories: partnersrelated and ICJV-related risks.

- Project risks (P) include the risk factors related to the performance of project, subdivided into five subcategories: organization, management, technical, contract, and design risks.

- External risks (E) refer to the risk factors related to external environment, subdivided into four subcategories: legal and political, social, economic, and force majeure risks.

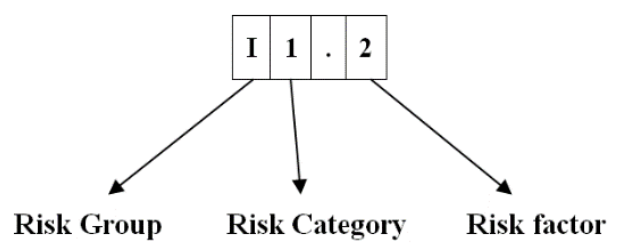

Fig. 3: Definition of risk code system

\subsection{Assess the risk factors throughout the lifecycle of ICJV projects}

Risk management is an ongoing process that continues during the lifecycle of a project. It includes processes for risk management planning, identification, analysis, monitoring, and control. Many of these processes are updated throughout project lifecycle as new risks can be identified at any time.

In this study, ICJV project lifecycle was subdivided into three stages that were proposed by Bing et al. (1999): (1) Startup; (2) Operation; (3) Dismantle. The startup stage of ICJV projects include two phases: beginning phase and formation phase (Prasitsom and Likhitruangsilp, 2011) beginning phase is the period from initial contacts between parent companies to ICJV startup, including negotiation and a signing agreement.

Formation phase is the period ICJV prepare bid proposal and submit bid to client. The operation stage refers to the stage of construction work being implemented. The dismantle stage is the period once most construction tasks have been completed, project is in the clean-up stage, and the participants start negotiating the ending matters.

The purpose of this paper is to try to understand the differences in the respondents' rating the level of risk factors over three stages of project. Fig. 5 illustrates three-dimensioned perspectives of risk (Probability, Impact, and Stage).

The probability (P) and the impact (I) of each risk factor that the respondents subjectively assessed in the questionnaire survey were then used to calculate the level of risk factors in the form of combined risk level (RL). Fig. 6, 7, and 8 display the risk contour diagrams of all 47 risk factors that are analyzed in three stages of ICJV projects. Table 3, 4, and 5 show the top 20 risk factors having high RL in difference stages of ICJV projects. We then focused on the assessment of these critical risk factors only. Finally, all of critical risk factors in difference phases of ICJVs are as follows in Fig. 9.

Subsequently, the analysis of risk factors throughout three stages of ICJV projects, namely startup, operation, and dismantle stages is as follows.

Startup stage: In the startup stage of ICJVs, among 20 risk factors in the top-level presented in Table 3, there were 18 critical risk factors (RL index more than 0.8). In this stage, project managers encountered with numerous risk factors. According to Gale and Luo (2004), startup stage contains important factors that lead to success or failure of a 
project. The startup stage of project can be subdivided into two phases: beginning and formation phase.

Beginning phase: The beginning phase expands from initial contacts between parent companies to ICJV startup, including set up its strategy, choose and then negotiate with the partners, and develop ICJV organization. It was found that risk factors affecting the beginning of ICJVs with high-risk levels, including partner's parent company in financial problems (I1.1), loss due to bureaucracy for late approvals (E2.5), language barrier (E2.2), socio-cultural, and religious differences (E2.3), interest rate (E3.4), inflation (E3.3), and economy fluctuation (E3.1). Financial issues of parents' partners and economics problems were the most concerned issue.

\section{Risk factors of ICJVs in Vietnam}

\section{Internal risk factors}

Partners-related risk (I1)
I1.1 - Partner's parent company in
financial problems
I1.2 - Policy changes in your partner's
parent company toward ICJV
I1.3 - Over-interference by parent
company of either partner
I1.4 - Change of organization within local
partner
I1.5 - Partner's lack of management
competence and resourcefulness
ICJVs-related risk (I2)
I2.1 - Disagreement on allocation of staff
positions in ICJV
I2.2 - Disagreement on allocation of
works
I2.3 - Technology transfer dispute
I2.4 - Breach of contracts by ICJV partner
I2.5 - Poor relation and disputes with
partner
I2.6 - Inadequate ICJV organization
structure
I2.7 - Poor relation with government
departments

\section{Risk factors of ICJVs in Vietnam}

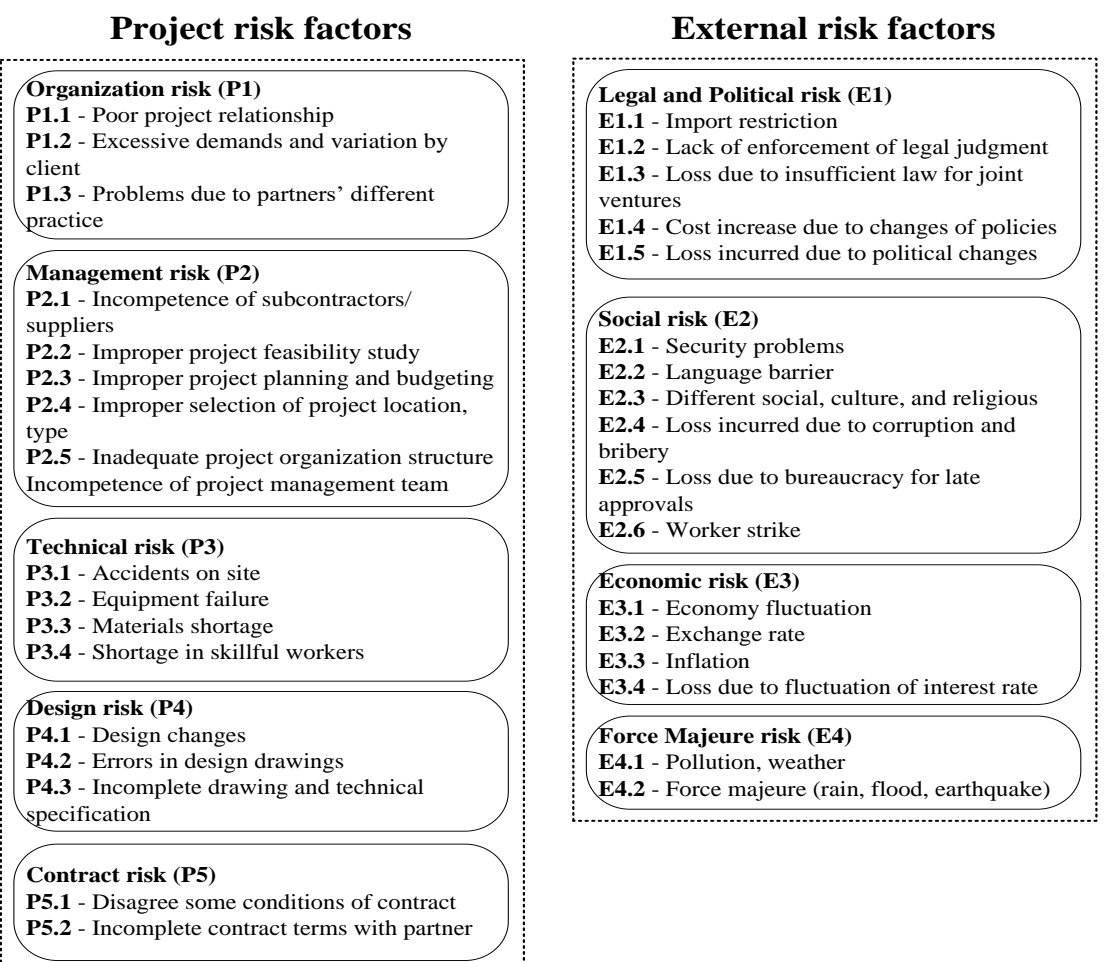

Fig. 4: Risk factors affecting ICJV projects in Vietnam

Therefore, it strongly requires parents' partners firms with financial capacity. Based on the composition of the JV, the partners from different nations may face cultural difference issues. The foreign companies bring their cultures, new technologies, and management systems to the new environment that may affect the existing culture. Thus, language barrier, socio-cultural, and religious was mentioned critical issue over the startup stage of ICJV projects. To summarize, it was found that the critical risk factors affecting the beginning phase of ICJVs such as capacity of parents' partners; language barrier; different social, culture; and economic problems.

Formation phase: Once the partners have been selected, it is almost certain that the ICJV is constituted and can be run. The ICJV then obtains bidding documents from the clients and prepare bid proposal. In this phase, it is also extremely complex due to the multifaceted organizations of ICJV, including initial ICJV, client, subcontractors, suppliers, and third parties. Among the 18 high-level risks of startup stage, there are five risk factors in internal risk group. These are partner's parent company in financial problems (I1.1), policy changes in your partner's parent company toward ICJV (I1.2), disagreement on allocation of staff positions in ICJV (I2.1), inadequate ICJV organization structure (I2.6), poor relation with government departments (I2.7), which were ranked $1^{\text {st }}, 17^{\text {th }}, 8^{\text {th }}, 14^{\text {th }}$, and $15^{\text {th }}$, respectively.

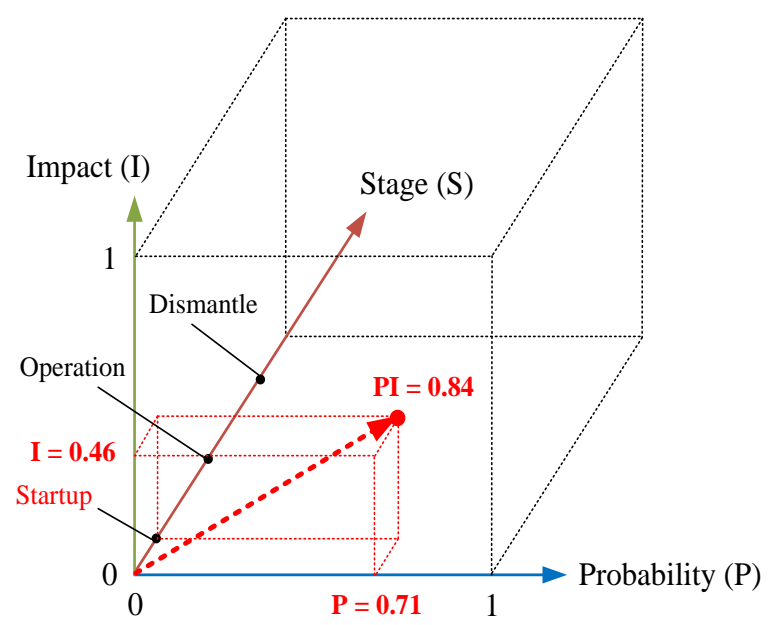

Fig. 5: Three-dimensioned perspectives (P, I, and S) of ICJV projects

The financial status of the JV partner's parent company is the most concerned issue in Vietnam. 
This is because it is currently affected by complex situation of inflation (E3.3), high interest rates (E3.4), and economic fluctuation (E3.1), which is a major challenge for managing any ICJV projects. According to Gale and Luo (2004), more than 84\% samples reported that the rights, responsibilities, and obligations of both parties were clearly defined in their JV agreement. However, these were not accurate with the current situation in Vietnam, leading to the disagreement in the allocation of staff position, inadequate organization structure, and even difficulty for implementation of ICJV upon the policy changes in partner's parent company (Sy and Likhitruangsilp, 2011).

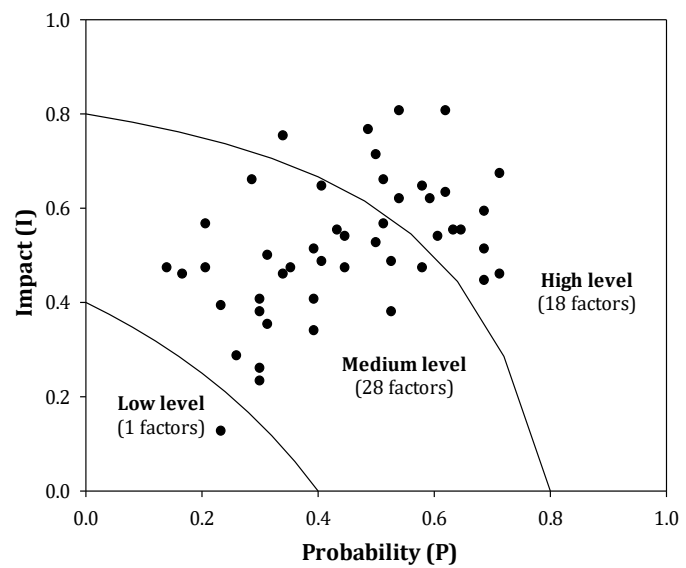

Fig. 6: Risk contour diagram of the risk factors in the startup stage

In addition, many issues related to omissions and negligence of architect/engineer of clients, such as improper selection of project location (P2.4), improper project feasibility study (P2.2), were greatly ranked $2^{\text {nd }}$ and $7^{\text {th }}$, respectively. In fact, Vietnamese companies often spend a little time and cost for feasibility studies, where the information is used very poorly and conjecturally, while international companies are willing to spend greater funds for this step. These factors can cause design changes (P4.1), and excessive demands and variation by client (P1.2) in the bidding process, which could be affected the performance of ICJV.

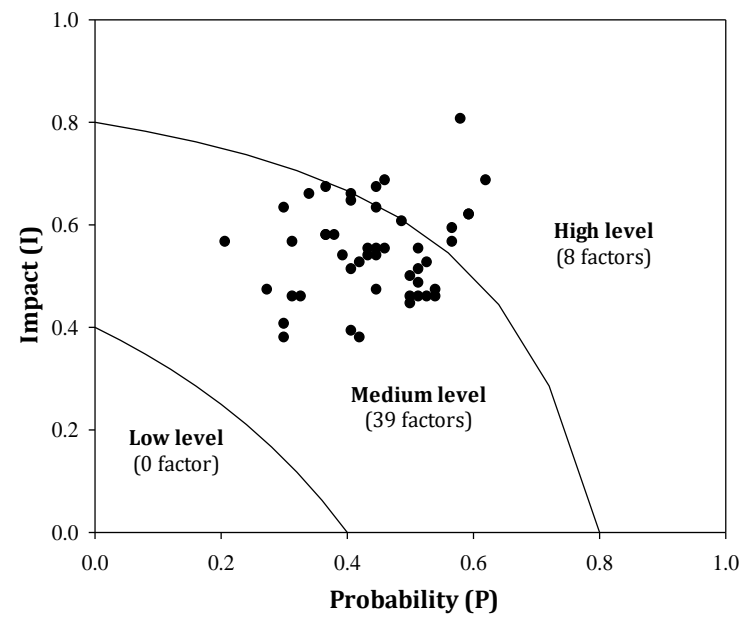

Fig. 7: Risk contour diagram of the risk factors in the operation stage

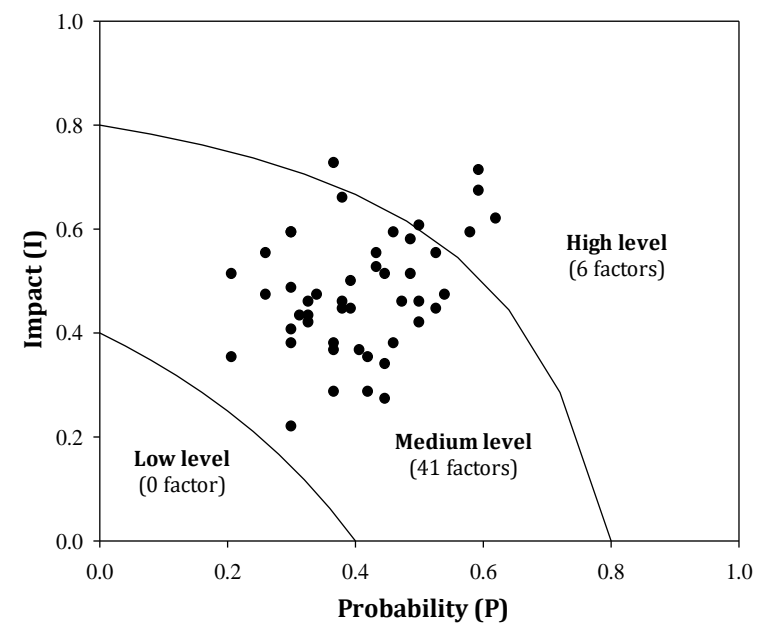

Fig. 8: Risk contour diagram of the risk factors in the dismantle stage

Table 3: Startup stage

\begin{tabular}{cclccc}
\hline Rank & ID & \multicolumn{1}{c}{ Risk factors } & P & I & RL \\
\hline 1 & I1.1 & Partner's parent company in financial problems & 0.62 & 0.81 & 0.927 \\
2 & P2.2 & Improper project feasibility study & 0.54 & 0.81 & 0.911 \\
3 & E2.5 & Loss due to bureaucracy for late approvals & 0.71 & 0.67 & 0.906 \\
4 & E3.1 & Economy fluctuation & 0.49 & 0.77 & 0.88 \\
5 & P4.1 & Design changes & 0.69 & 0.59 & 0.873 \\
6 & E3.3 & Inflation & 0.62 & 0.63 & 0.861 \\
7 & P2.4 & Improper selection of project location, type & 0.5 & 0.71 & 0.857 \\
8 & I2.1 & Disagreement on allocation of staff positions in ICJV & 0.58 & 0.65 & 0.852 \\
9 & E2.2 & Language barrier & 0.69 & 0.51 & 0.848 \\
10 & E3.4 & Loss due to fluctuation of interest rate & 0.59 & 0.62 & 0.845 \\
11 & E2.3 & Socio-cultural, and religious differences & 0.71 & 0.46 & 0.845 \\
12 & E1.3 & Loss due to insufficient law for joint ventures & 0.65 & 0.55 & 0.842 \\
13 & P1.2 & Excessive demands and variation by client & 0.34 & 0.75 & 0.837 \\
14 & I2.6 & Inadequate ICJV organization structure & 0.63 & 0.55 & 0.836 \\
15 & I2.7 & Poor relation with government departments & 0.51 & 0.66 & 0.835 \\
16 & E2.4 & Loss incurred due to corruption and bribery & 0.69 & 0.45 & 0.827 \\
17 & I1.2 & Policy changes in your partner's parent company toward ICJV & 0.54 & 0.62 & 0.825 \\
18 & P5.1 & Disagree some conditions of contract & 0.61 & 0.54 & 0.819 \\
19 & P2.5 & Inadequate project organization structure & 0.41 & 0.65 & 0.79 \\
20 & I2.2 & Disagreement on allocation of works & 0.51 & 0.57 & 0.789 \\
\hline
\end{tabular}


Table 4: Operation stage

\begin{tabular}{cclccc}
\hline Rank & ID & & P & I & RL \\
\hline 1 & I1.1 & Partner's parent company in financial problems & 0.58 & 0.81 & 0.919 \\
2 & E3.3 & Inflation & 0.62 & 0.69 & 0.881 \\
3 & P2.1 & Incompetence of subcontractors/suppliers & 0.59 & 0.67 & 0.867 \\
4 & E3.4 & Loss due to fluctuation of interest rate & 0.59 & 0.62 & 0.845 \\
5 & P2.6 & Incompetence of project management team & 0.46 & 0.69 & 0.831 \\
6 & P4.1 & Design changes & 0.57 & 0.59 & 0.824 \\
7 & P2.3 & Improper project planning and budgeting & 0.45 & 0.67 & 0.819 \\
8 & P1.2 & Excessive demands and variation by client & 0.57 & 0.57 & 0.812 \\
9 & I2.7 & Poor relation with government departments & 0.41 & 0.66 & 0.798 \\
10 & E3.1 & Economy fluctuation & 0.49 & 0.61 & 0.798 \\
11 & I1.2 & Policy changes in your partner's parent company toward ICJV & 0.45 & 0.63 & 0.797 \\
12 & I2.4 & Breach of contracts by ICJV partner & 0.37 & 0.67 & 0.793 \\
13 & P2.5 & Inadequate project organization structure & 0.41 & 0.65 & 0.79 \\
14 & P3.4 & Shortage in skillful workers & 0.51 & 0.55 & 0.783 \\
15 & E3.2 & Exchange rate & 0.53 & 0.53 & 0.776 \\
16 & P2.2 & Improper project feasibility study & 0.34 & 0.66 & 0.776 \\
17 & P4.2 & Errors in design drawings & 0.51 & 0.51 & 0.763 \\
18 & I2.6 & Inadequate ICJV organization structure & 0.46 & 0.55 & 0.759 \\
19 & E2.5 & Loss due to bureaucracy for late approvals & 0.54 & 0.47 & 0.758 \\
20 & E1.3 & Loss due to insufficient law for joint ventures & 0.45 & 0.55 & 0.753 \\
\hline
\end{tabular}

Table 5: Dismantle stage

\begin{tabular}{cclccc}
\hline \multicolumn{1}{c}{ Table 5: Dismantle stage } & \multicolumn{1}{c}{ Risk factors } & $\mathrm{P}$ & $\mathrm{I}$ & $\mathrm{RL}$ \\
\hline Rank & ID & & 0.59 & 0.71 & 0.883 \\
2 & I1.1 & Partner's parent company in financial problems & 0.62 & 0.66 & 0.871 \\
3 & E3.3 & Inflation & 0.59 & 0.67 & 0.867 \\
4 & P2.1 & Incompetence of subcontractors/suppliers & 0.58 & 0.61 & 0.835 \\
5 & P4.1 & Design changes & 0.37 & 0.73 & 0.827 \\
6 & E2.4 & Loss incurred due to corruption and bribery & 0.5 & 0.61 & 0.803 \\
7 & P4.2 & Errors in design drawings & 0.38 & 0.66 & 0.789 \\
8 & E3.2 & Exchange rate & 0.53 & 0.55 & 0.789 \\
9 & E3.1 & Economy fluctuation & 0.49 & 0.58 & 0.784 \\
10 & P2.6 & Incompetence of project management team & 0.46 & 0.59 & 0.78 \\
11 & E2.5 & Loss due to bureaucracy for late approvals & 0.54 & 0.47 & 0.758 \\
12 & P3.4 & Shortage in skillful workers & 0.49 & 0.51 & 0.75 \\
13 & I2.5 & Poor relation and disputes with partner & 0.43 & 0.55 & 0.747 \\
14 & P1.3 & Problems due to partners' different practice & 0.53 & 0.45 & 0.738 \\
15 & P5.1 & Disagree some conditions of contract & 0.43 & 0.53 & 0.732 \\
16 & E1.3 & Loss due to insufficient law for joint ventures & 0.45 & 0.51 & 0.731 \\
17 & I2.1 & Disagreement on allocation of staff positions in ICJV & 0.5 & 0.46 & 0.73 \\
18 & P3.3 & Materials shortage & 0.47 & 0.46 & 0.716 \\
19 & P2.4 & Improper selection of project location, type & 0.3 & 0.59 & 0.715 \\
20 & E4.2 & Force majeure (rain, flood, earthquake) & 0.3 & 0.59 & 0.715 \\
\hline
\end{tabular}

Besides, language barrier (E2.2), socio-cultural, and religious differences (E2.3), and bureaucracy for late approvals (E2.5), corruption and bribery (E2.4) influence significantly on the ICJV startup stage. Bureaucracy, corruption, and bribery issues in approving projects in Vietnam have become an implicit "culture" which may not be acknowledged by numerous international companies. According to the recent survey by Ernst \& Young, up to $96 \%$ of Vietnam business confirmed that concerning bribery and corruption, they especially did not think spending more money for the relationship with the government departments would be major obstacles to business activities.

Operation stage: During this period, construction works are performed until most construction works are completed. As can be seen in Table 4, eight critical risk factors were identified, including the parent partners' financial aspects (I1.1), project management limitation (P2.6, P2.3), poor capacity of subcontractors/suppliers (P2.1), extreme variation and changes (P1.2, P4.1) and economic problems (E3.3, E3.4). Critical risk factors in operation stage were divided into three main problems.
Management problems: Three main elements in this category namely incompetence of project management team (P2.6), improper project planning and budgeting (P2.3), and excessive demands and variation by client (P1.2), were ranked $5^{\text {th }}, 7^{\text {th }}$, and $8^{\text {th }}$, respectively. The basic cause of these risk factors is incompetent management of ICJVs in Vietnam. The ICJV projects are usually very large and complex. A large number of parties, including contractors, nominated subcontractors, and subcontractors/ suppliers are associated with projects. The relationship and information stream among the participants are very complicated. Thus, inadequate and incompetent coordination among parties is a major cause of the problems. Moreover, excessive demands and variation by client should effect to potential change of work allocation within partners, the disruption of work and associated claims. Therefore, the participants executing ICJV projects need to be prepared to face this problem.

Subcontractors and suppliers: Currently there are many ICJV project activities related to the subcontractors and suppliers. Zou et al. (2007) found that most risks in construction phase are related directly to contractors and subcontractors. 
According to Sy and Likhitruangsilp (2011), inadequate and incompetent coordination among parties was a major cause of the problems. Incompetence of subcontractors/suppliers was mentioned as a critical risk factor in operation stage, which was in the third rank.

Since inequity and fraud in the bidding process were a very common problem in Vietnam (Long et al., 2004), the awarded subcontractors were often labeled "incompetent". In addition, unfamiliar cooperation between contractors and subcontractors/suppliers and among each other subcontractors may cause the difficulty in managing projects.

Economic conditions: These risk factors are considered macroeconomic conditions that are unavoidable. The high inflation and fluctuation of interest rates that enormously affected construction contract price were ranked $2^{\text {nd }}$ and $4^{\text {th }}$, respectively. Moreover, these factors were emphasized to have some important impacts on cost, time, quality, and scope of ICJV projects.

In fact, these factors could have a great impact on the profit or loss of the participants in ICJVs (Bing et al., 1999). In 2008 and 2009, global economic crisis had the bad effects to the implementation of construction projects in Vietnam. The nation's inflation rate recently increased more than $18 \%$ in 2011, which enormously affected the prices of all construction resources. Moreover, high inflation has pushed total investment of ICJV projects increased beyond $10 \%$ backup funds. These issues were the causes of financial aspects are the most concern issue by respondents. Thus, the participants executing ICJV projects need to be prepared to face this problem.

Dismantle stage: The survey results in Table 5 show that there just have six critical risk factors in dismantle stage. It is clear that when the project is near completion, the risk exposure would be reduced correspondingly. There are, however, a number of existing problems to be concerned. First are financial problems of main contractor and delayed payment to subcontractors. Moreover, in the final stage of ICJV projects, the conflict between profit and loss of clients, main contractors, subcontractors, and suppliers culminated. The clients would like to finish their projects in a short time, and to make use of the project for its intended purpose.

While the main contractors and subcontractors desire their work completion and receive all of owner's payments, the contractors may face delayed payments and sometimes nonpayment risk of clients. In addition, due to the inevitable effects of inflation and volatility of interest rates, not only the contractor but clients also affected significantly on the schedule of project as planned. Furthermore, the negligence and weakness of subcontractors may also cause the difficulty of finishing processes. Excessive demands and variation by client, design changes are also headaches for contractors in this stage.

\subsection{Discussion in overall of ICJV projects in Vietnam}

According to the evaluation of respondents about critical risk factors in different stages of the ICJV projects, it was noted that the risk factors such as partner's parent company in financial problems, design changes, inflation, and fluctuation of interest rate was assessed as high influence. Indeed, they were the most concerned issues in Vietnam. It is logical because of the rapid economic development of Vietnam, financial and economic issues greatly affected the implementation of ICJV projects

Especially, this paper also shows that the startup stage contains many issues within the huge influence to the success or failure of ICJV projects. There are the intrinsic factors in ICJV organization and some factors of project risks group such as inadequate ICJV organization structure, policy changes in your partner's parent company, and disagreement on allocation of staff positions, improper project feasibility study, different culture, and insufficient law for ICJV. Financial matters, policies changes, and cultural differences are the issues pointed out by the most respondents to have huge effect on the implementation of ICJV projects. Moreover, the Vietnamese legal system and regulations are very complicated (Long et al., 2004) and some of them contradict with each other. It is therefore very difficult to deal and comply throughout the regulations, especially JV laws in Vietnam. Therefore, both parties of ICJV projects should be aware with these issues in the startup stage as well as the later stage of ICJV projects.

Continuity, in the operation and dismantle stage, the issue of incompetence of subcontractors/ suppliers was mostly mentioned by respondents. To mitigate these risk factors, it is necessary to enhance the capability and qualification of subcontractors and suppliers in the startup stage for ICJV projects.

Bureaucracy, corruption, and bribery are also the most concerned issue in Vietnamese ICJV projects. As can be seen, these risk factors was assessed a huge influence to the startup and dismantle stages. Indeed, the corruption and bribery in Vietnam are still at an alarm rate. The reason is that Vietnamese companies are not well-informed of the complicated law and/or intentionally commit the crimes as a way to avoid any further plagues by administration officials. The legal procedures in Vietnam are quite difficult because of the popularity of bureaucracy, corruption, and bribery. It was noted that the foreign contractors might not acknowledge with bureaucracy in Vietnam. Thus, the ICJV companies need prepare to face these issues.

\subsection{Trend analysis in different stages of ICJV projects}

The tendency of each risk factors group was calculated by formula (2). The develop trends indexes of probability (P), impact (I), and combined risk level (RL) are then shown in Table 6, 7, and 8. 
Moreover, the trend analysis details of probability, impact, and degree of risk groups are as shown in Fig. 10.

Internal risk group: In the three-stage development of an ICJV, the probability indexes of internal risk group fall down from startup to dismantle as shown in Table 6 . It can be said that organization of an ICJV is accompanied by a large number of matters such as negotiate to make the agreement contract, language barrier, unsuitable organization structure. Conflicts could arise during negotiation, and if the parties cannot reach an agreement, ICJV cannot be continued. Moreover, according to Gale and Luo (2004), more than $70 \%$ of partners in JV had no previous relationship with each other before the negotiations to establish JV.

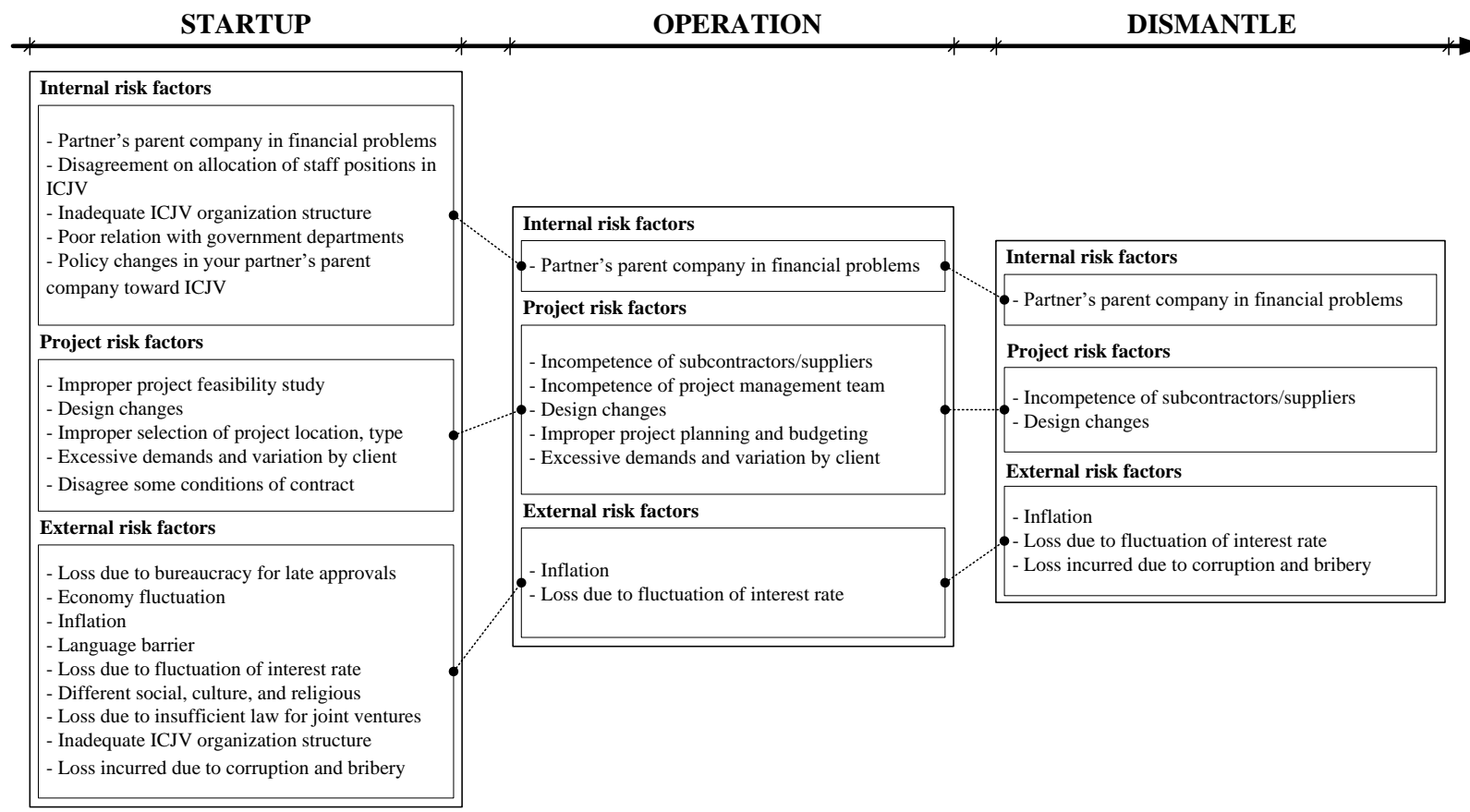

Fig. 9: Critical risk factors in difference stages of performance of ICJVs in Vietnam
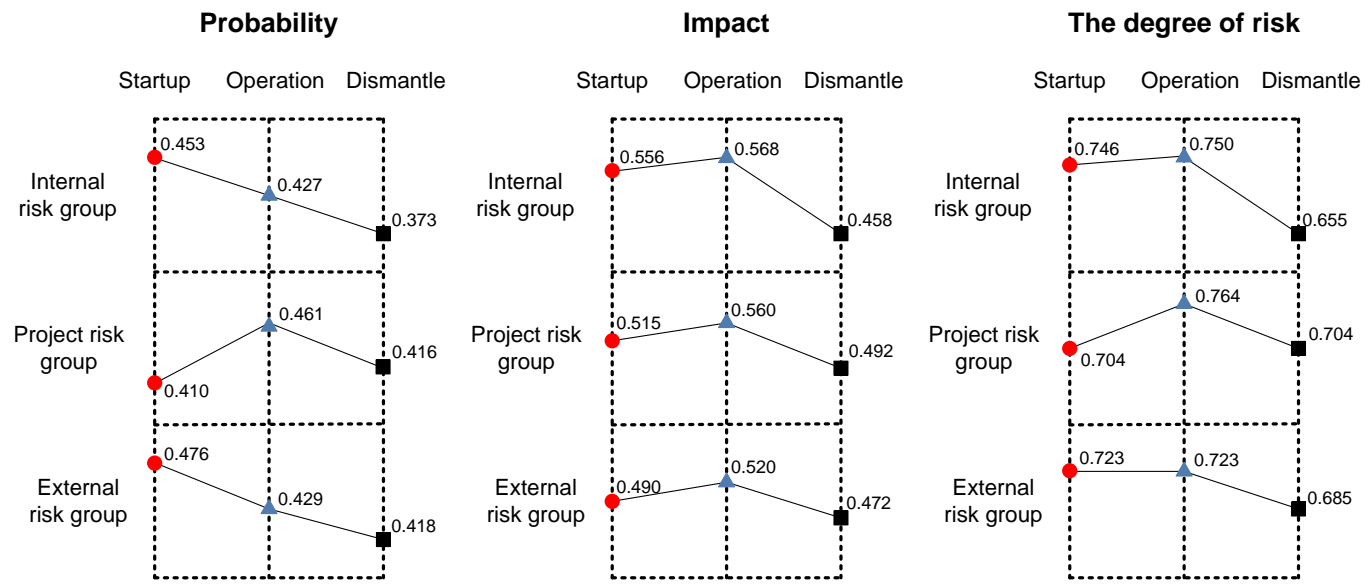

Fig. 10: Trend analysis of probability, impact, and the degree of risk groups in the life cycle of project

Table 6: Risk probability in different stages of ICIVs

\begin{tabular}{cccc}
\hline & Startup & Operation & Dismantle \\
\hline Internal risk group & 0.453 & 0.427 & 0.373 \\
Project risk group & 0.41 & 0.461 & 0.416 \\
External risk group & 0.476 & 0.429 & 0.418 \\
\hline
\end{tabular}

Table 7: Risk impact in different stages of ICJVs

\begin{tabular}{cccc}
\hline & Startup & Operation & Dismantle \\
\hline Internal risk group & 0.556 & 0.568 & 0.458 \\
Project risk group & 0.515 & 0.56 & 0.492 \\
External risk group & 0.49 & 0.52 & 0.472 \\
\hline
\end{tabular}

Therefore, it is very difficult in cooperation among the partners of ICJV. As can be seen, risk factors would be inevitable and have the huge impact $(I=0.556)$ as follows in Table 7 . Consequently, the degree of this group would be rated high in operation and startup stages where the financial problems of the ICJV organization and policy changes in your partner's parent company with having high-risk probability and impact are most concerned issues.

Table 8: Combined risk levels in different stages of ICJVs

\begin{tabular}{cccc}
\hline & Startup & Operation & Dismantle \\
\hline Internal risk group & 0.746 & 0.75 & 0.655 \\
Project risk group & 0.704 & 0.764 & 0.704 \\
External risk group & 0.723 & 0.723 & 0.685 \\
\hline
\end{tabular}


Project risk group: In the project risk group, the probability of this group had its medium value of 0.410 , in the startup stage. Risks would become significance when projects was be carried out, its probability increase of 0.461 which is most critical of probability of all stages. Until project was near completion, it falls over to low value of 0.416 . The development of risk impact of project group had the same trend with its probability as shown in Fig. 10. As can be seen, the project risk group in the operation stage has high degree of probability and impact. As a result, its risk degree index reaches the highest value of 0.764 . When a project is being executed, the more capital, material, and labor would be spent, the more risky might appear in the construction process during the life cycle of project. Therefore, it can be noted that the project organizations need to focus to solve risk factors of the specific project.

External risk group: These risk factors are considered exterior conditions and impossible to avoid. The result of this paper shows that the highest probability of external risk group is of 0.476 in the startup stage. It then falls to 0.429 in the operation stage and 0.418 in the dismantle stage. This is because in the startup stage, parties may encounter within new environment, the ICJV set up under government laws and regulations, language barrier and different culture, and even security problems. The probability of these issues might diminish until the project completion. However, level of impact of this group is reflected highest in the operation stage. Thus, we must to pay attention to huge impact of this risk group in operation stage of project. The instability economic problems at high interest rates and inflation are primarily alarmed. Finally, from startup to operation, the level of risk factors (RL) are mentioned very large influence to ICJV projects. Especially, since project was initiated and constructed, risk factors, if any occurs, will affect project completion.

\section{Conclusion}

This paper identified the risk factors affecting the ICJV performance throughout different stages of ICJV projects in Vietnam. Data were collected by surveying 15 experienced professionals who have worked for ICJV projects in Vietnam. It is important to know the risk factors that foreign and domestic firms face and also to assess the significant risk factors due to limited research works investigated risk management related to the life cycle of ICJV projects in Vietnam.

Risks associated with the ICJV projects in Vietnam are extremely critical and different from other types of construction business form. Based on the results of this study, the 47 risk factors affecting the ICJV performances were identified and assessed. Our results show that the critical risk factors were various throughout the life cycle of ICJV projects in Vietnam. The critical risk factors throughout three stages of ICJV projects were identified as follows:
- Startup stage: partners' parent financial and ICJV organization aspects; architects/engineers problems; language barrier; different social, culture; bureaucracy, corruption and bribery; and economic conditions.

- Operation stage: partners' parent financial, management problems, incompetence subcontractors and suppliers, and economic conditions.

- Dismantle stage: partners' parent financial aspects, incompetence subcontractors and suppliers, and economic conditions.

Financial matters, policies changes, and cultural difference are the issues with the most respondents pointed out huge effect on implementation in the startup stage of ICJV projects. Moreover, the Vietnamese legal system and regulations are very complicated and some of them contradict with each other. It is therefore very difficult to deal and comply with the regulations, especially JV laws in Vietnam. Therefore, both parties of ICJV projects should be aware of these issues in the startup stage as well as the later stage of ICJV projects.

Continuity, in the operation and dismantle stages, the issue of incompetence of subcontractors/ suppliers was mostly mentioned by respondents. To mitigate these risk factors, it is necessary to enhance the capability and qualification of subcontractors and suppliers in the startup stage for ICJV projects.

Finally, the tendency of risk factor groups in different stages of ICJV projects have been adopted to help the project managers having an appropriate risk management strategy throughout the lifecycle of ICJVs in Vietnam.

\section{Acknowledgment}

The authors would like to thank the ASEAN University Network/Southeast Asia Engineering Education Development Network (AUN/SEED-net JICA), Chulalongkorn University (CU), Bach Khoa University (BKU), and Hochiminh City Open University (HCMCOU) for their financial support to this paper.

\section{References}

Andrew KHC, Then D, and Skitmore M (2000). Risk management in Singapore construction joint ventures. Journals of Construction Research, 1(2): 139-149.

Beamish PW (1993). The characteristics of joint ventures in the People's Republic of China. Journal of International Marketing, 1(2): 29-48.

Bing L, Tiong RLK, Fan WW, and Chew DAS (1999). Risk Management in International Construction Joint Ventures. Journal of Construction Engineering and Management, 125(4): 277-284

Dale CF (2005). Project risk management guidelines: Managing risk in large projects and complex procurements. John Wiley \& Sons Inc., Hoboken USA.

Ezeldin AS and Orabi W (2006). Risk identification and response methods: Views of large scale contractors working in developing countries. In: Pandey M, Xie WC, and Xu L (Eds.), 
Advances in Engineering Structures, Mechanics and Construction: 781-792. Springer, Amsterdam, Netherlands.

Flanagan R and Norman G (1993). Risk management and construction. John Wiley and Sons, Hoboken, USA.

Gale A and Luo J (2004). Factors affecting construction joint ventures in China. International Journal of Project Management, 22(1): 33-42.

Geringer JM and Hebert L (1991). Measuring performance of international joint ventures. Journals of International Business Studies, 22(2): 249-264.

Han SH, Kim DY, Kim H, and Jang WS (2008). A web-based integrated system for international project risk management. Automation in Construction, 17(3): 342-356.

Long ND, Ogunlana S, Quang T, and Lam KC (2004). Large construction projects in developing countries: A case study from Vietnam. International Journal of Project Management, 22(7): 553-561.

Ozorhon B, Dikmen I, and Birgonul MT (2007). Using analytic network process to predict the performance of international construction joint ventures. Journal of Management in Engineering, 23(3): 156-163.

Prasitsom A and Likhitruangsilp V (2011). Design of administrative structures for construction joint ventures. In: Kobayashi K, Rashid KA, Onishi M, and Hasan SF (eds.), Joint Ventures in Construction 2: Contract, governance, performance and risk. Thomas Telford, London, UK.
Sameh ME (2008). Risk assessment and allocation in the UAE construction industry. International Journal of Project Management, 26(4): 431-438.

Shen LY, Wu GWC, and Ng CS (2001). Risk assessment for construction joint ventures in China. Journal of construction engineering and management, 127(1): 76-81.

Smith NJ, Merna T, and Jobling P (1999). Managing risk in construction projects. Blackwell Science, Hoboken, USA.

Soghe AF, and Balasbaneh EA (2015). Factors affecting on tax subservient in the tax audit based risk. International Journal of Advanced and Applied Sciences, 2(12), 37-41.

Sy DT and Likhitruangsilp V (2011). Ranking critical risk factors of international construction joint ventures in Vietnam. In the $7^{\text {th }}$ International Conference on Multi-National Joint Venture for Construction Works, Bandung, Indonesia.

Wang SQ, Dulaimi MF, and Aguria MY (2004). Risk management framework for construction projects in developing countries. Construction Management and Economics, 22(3): 237-252.

Zhang G and Zou PX (2007). Fuzzy analytical hierarchy process risk assessment approach for joint venture construction projects in China. Journal of Construction Engineering and Management, 133(10): 771-779.

Zhi H (1995). Risk management for overseas construction projects. International Journal of Project Management, 13(4): 231-237.

Zou PX, Zhang G, and Wang J (2007). Understanding the key risks in construction project in China. International Journal of Project Management, 25(6): 601-614. 